Gut, 1963, 4, 30

\title{
Duodenal diverticula and haemorrhage
}

\author{
M. J. S. LANGMAN
}

From the Department of Gastroenterology, Central Middlesex Hospital, London

EDITORIAL SYNOPSIS A controlled study has been made of the frequency of the association between duodenal diverticula and upper intestinal haemorrhage. No correlation was found between them.

Duodenal diverticula are often stated to cause haemorrhage (Herrington, 1958; Sheldon, Lazar, Richards, and Henegar, 1959), and operation has been advocated (Forrest, 1957) when there is recurrent upper intestinal bleeding and a duodenal diverticulum is the only demonstrable abnormality. This study was designed to investigate the possibility that a significant correlation exists between haemorrhage and duodenal diverticulosis.

\section{MATERIAL AND METHOD}

A detailed record has been kept in this unit since 1941 of all cases admitted with haematemesis and melaena to this large general hospital. From all such patients who had radiographs taken were selected those who had no radiological abnormality or had duodenal diverticula only. The group rejected was composed of all with a possible local cause for bleeding, such as peptic ulcer, and all with a generalized bleeding tendency. The 605 patients who were selected in this way were allocated to successive quinquennial age groups after separation by sex (Table). Each group was then matched with equal numbers of control cases of the same sex and age group taken from the routine barium meal books of this hospital for 1953 and 1955 . These books contain records of all barium meals done during the year in the X-ray Department. The controls were restricted by the exclusion of patients with a hiatus hernia, as it has been suggested (Jones and Merendino, 1960) that there is an association between hiatus hernia and duodenal diverticulosis. Barium meals done on patients after gastric surgery were also rejected. All other barium meals, whether normal or abnormal, were included.

\section{RESULTS AND CONCLUSIONS}

The table shows the general age and sex distribution of the groups in which diverticula were found for both the haemorrhage and control series.

It will be seen that the age and sex distribution of patients with duodenal diverticula is the same for the haemorrhage and control populations, and that 22 from the haemorrhage and 23 from the control group, each comprising 605 cases, had diverticula. It is therefore clear that there is no statistical correlation between the presence of duodenal diverticula and liability to haemorrhage into the gut, although this does not deny that a causal relationship may exist in rare cases.

In another study Forrest (1957) found a highly

T A B L E

\begin{tabular}{|c|c|c|}
\hline \multirow{3}{*}{$\begin{array}{c}\text { Age Group } \\
\text { (yr.) }\end{array}$} & \multicolumn{2}{|l|}{ Male } \\
\hline & Total No, in Each Group & No. with Diverticula \\
\hline & & Haemorrhage \\
\hline
\end{tabular}

\section{Female}

Total No. in Each Group No. with Diverticula Haemorrhage Control

\begin{tabular}{ll}
\hline Under 20 & \\
$20-24$ & 1 \\
$25-29$ & 1 \\
$30-34$ & 27 \\
$35-39$ & 23 \\
$40-44$ & 23 \\
$45-49$ & 37 \\
$50-54$ & 4 \\
$55-59$ & 34 \\
$60-64$ & 32 \\
$65-69$ & 36 \\
Over 70 & 32
\end{tabular}

$\bar{Z}$
$\bar{z}$
$\overline{1}$
$\overline{3}$

$\begin{array}{ll}\overline{ } & = \\ = & \\ \overline{7} & = \\ \frac{1}{2} & = \\ 2 & 1 \\ 3 & 1 \\ 5 & 3 \\ 13 & 7\end{array}$

$=$
$=$
$=$
$\overline{1}$
1
3
7
13


significant correlation between haemorrhage and diverticulosis. On this basis he suggested that operation should be considered when there is recurrent bleeding and a duodenal diverticulum is the only manifest abnormality. In that survey, however, there was no matching for age and sex between the haemorrhage and control populations. It is conceivable that if this had been done the difference would have been eliminated, for it can be seen from the present study that diverticula are more commonly discovered in elderly patients. Also, diverticula are more often found in women than in men, at least at this hospital (Pygott, 1962). Certainly there is no mathematical justification from the present results for surgical removal of duodenal diverticula when there is recurrent intestinal haemorrhage.

The suggested association between hiatus hernia and duodenal diverticulosis (Jones and Merendino, 1960) could be accounted for when it is realized that duodenal diverticula most commonly occur in elderly women. It is probable that this tendency is also true for hiatus hernia, which would reasonably explain a coincidence between the two conditions.

I am most grateful to Miss B. White, librarian to the Department of Gastroenterology, and to Dr. F. Pygott, consultant radiologist to the Central Middlesex Hospital, for their help in this study.

\section{REFERENCES}

Forrest. A. D. (1957). Incidence of bleeding in duodenal diverticula. Gastroenterology, 33, 800-806.

Herrington, J. L. (1958). Massive haemorrhage resulting from benign ulceration in a primary duodenal diverticulum. Surgery, 43, 340-344.

Jones, T. W., and Merendino, K. A. (1960). The perplexing duodenal diverticulum. Ibid., 48, 1068-1084.

Pygott, F. (1962). Personal communication.

Sheldon, W. C., Lazar, H. P., Richards, J. W., and Henegar, G. C (1959). Gastrointestinal haemorrhage from duodenal diverticula. Amer. J. dig. Dis., n.s. 4, 817-821. 